\title{
OPERÁRIO PADRÃO: O MODELO DE TRABALHADOR SEGUNDO OS EMPRESÁRIOS INDUSTRIAIS DURANTE A DITADURA MILITAR BRASILEIRA
}

\author{
OPERÁRIO PADRÃO: THE MODEL WORKER ACCORDING TO \\ INDUSTRIAL ENTREPRENEURS DURING THE BRAZILIAN \\ MILITARY DICTATORSHIP
}

DOI: http//dx.doi.org/10.15448/21778-3748.2018.2.26379

\author{
Daniela de Campos \\ Daniela de Campos - IFRS \\ dcampos7@hotmail.com
}

\begin{abstract}
RESUMO: Este trabalho é resultado de pesquisa realizada para tese de doutoramento em História defendida em 2014 no Programa de Pós-Graduação em História da Pontifícia Universidade Católica do Rio Grande do Sul (PUCRS). A Campanha Operário Padrão iniciou ainda na década de 1950, circunscrita ao Estado do Rio de Janeiro. Na década seguinte, já sob a ditadura militar, o Serviço Social da Indústria (SESI), uma entidade patronal, aliouse ao jornal $O$ Globo para tornar o concurso nacional. Conforme a historiadora estadunidense Bárbara Weinstein (1995), a Campanha ou Concurso Operário Padrão foi uma das ações mais importantes do SESI após o golpe civilmilitar de 1964, que instaurou uma ditadura militar no país, pois sua inserção no concurso para premiar um operário modelo foi uma das poucas inovações implantadas após 1964, uma vez que o contexto político favorecia esse tipo de investida. Assim, entende-se que a existência de um concurso que premiava o operário modelo, segundo preceitos dos empresários industriais, foi um instrumento que visava disciplinar os trabalhadores - não somente aqueles que participaram do concurso, mas especialmente os demais, por meio do exemplo imposto pelo operário modelo. A pesquisa apresentada possibilitou perceber que o concurso era, acima de tudo, uma exaltação do trabalho, do labor constante e dedicado em uma sociedade que necessitou "reabilitar o valor do trabalho", especialmente nos anos 30 do século passado.
\end{abstract}

Palavras-chave: Operário Padrão. SESI. Trabalho.

ABSTRACT: This work is the result of a research carried out for a doctoral thesis in History defended in 2014, in a Post-Graduate Program in History of PUCRS. The Standard Worker Campaign began in the 1950s, restrict to the state of Rio de Janeiro. In the following decade, already under the military dictatorship, the Social Service of Industry - SESI, a industrial institution, allied itself with the newspaper to turn into a national competition. According to American historian Barbara Weinstein, the Campaign or Contest "Operário Padrão" was one of the most important actions of SESI, following the 1964 civil-military strike, which established a military dictatorship in the country, since its inclusion in the competition to reward a model worker was one of the few innovations implemented after 1964, since the political context favored this type of action. Thus, it is understood that the existence of a competition that rewarded the model worker, according to industrial entrepreneurs's precepts, was an instrument aimed at disciplining workers, not only those who participated in the contest, but especially the others, through the example imposed by the Model worker. The research made it possible to perceive that the contest was, above all, the exaltation of work, constant and dedicated work and this in a society that needed to "rehabilitate the value of work", especially in the 30 s of last century.

KEYWORDS: Operário Padrão; SESI; Work. 
O presente texto aborda a construção de um modelo de trabalhador sob a ótica do empresariado nacional por meio de um concurso nacional, o Operário Padrão. Para tal, entendese que a Campanha Operário Padrão foi um instrumento que visava disciplinar os trabalhadores - não somente aqueles que participaram do concurso, mas especialmente os demais - por meio do exemplo imposto pelo operário modelo. Assim, as regras criadas pelos promotores da campanha tendiam a escolher e, de certa forma, "fabricar" um modelo a ser seguido pelos outros e, por conseguinte, disciplinar a mão de obra industrial.

\section{O CONCURSO}

No filme O homem que virou suco (1979), de João Batista Andrade, apresenta-se ao espectador uma oposição entre diferentes tipos de trabalhadores: aquele que se conformava ao sistema da fábrica e adere a uma lógica social alheia a sua classe, e, em contraposição, o trabalhador que, apesar de várias tentativas, não consegue se enquadrar na disciplina do trabalho. Nessa obra ficcional, os dois personagens são vividos pelo mesmo ator, José Dumont.

A primeira cena do filme se passa em uma cerimônia de premiação do Operário Padrão do Estado de São Paulo. O personagem José Severino da Silva foi o vencedor do concurso do ano de 1979 e ali estava para receber o prêmio. A encenação prossegue com o presidente da Federação das Indústrias do Estado de São Paulo (FIESP), que, momentos antes de anunciar o vencedor, profere algumas palavras aos trabalhadores e empresários que lá se encontravam, afirmando que para "sermos uma grande nação precisamos da vossa [dos operários] constante dedicação ao trabalho, de vossa assiduidade, de vossa responsabilidade em relação à família. Do elevado grau de companheirismo, do respeito aos princípios e às leis que regem o país" (O HOMEM..., 1979). Após esse discurso, Severino é anunciado como o vencedor daquele ano. Ele levanta, beija sua esposa, dirige-se até seu patrão e o esfaqueia. ${ }^{1}$

Excetuando o assassinato do dono da empresa pelo operário padrão fictício, o trecho do filme descrito acima pode muito bem sintetizar as características e objetivos da Campanha Operário Padrão. A obra segue contrapondo (de forma subjetiva, pois José Severino pouco aparece nas cenas seguintes) os dois modelos de operários apresentados, enaltecendo a não adequação e a resistência ao trabalho do personagem Deraldo, a antítese de Severino.

Considerando que se trata de uma obra de ficção, o filme pode ser uma alegoria de como os trabalhadores vêm sendo apresentados pelas pesquisas acadêmicas no campo da História no

\footnotetext{
${ }^{1}$ A cena foi, de fato, gravada durante a cerimônia de entrega do prêmio, excetuando a última parte, em que Severino esfaqueia seu patrão.
} 
Brasil: há muito mais trabalhos sobre o trabalhador combativo, sindicalizado, do que sobre os demais. Podemos, assim, pressupor que os que apresentavam tal perfil eram e são a maioria entre os operários? Acredita-se, dessa forma, que o conhecimento sobre o concurso aqui analisado pode auxiliar um entendimento mais abrangente dos trabalhadores brasileiros, como explicita Weinstein:

A Campanha Operário Padrão, foi, inicialmente, um empreendimento exclusivo do jornal O Globo, tendo iniciado ainda na década de 1950, circunscrito ao estado do Rio de Janeiro. Na década seguinte, já sob a ditadura militar, o Serviço Social da Indústria - SESI aliou-se ao jornal para tornar o concurso nacional. (WEINSTEIN, 2000, p. 351).

Conforme Weinstein (2000), após 1964 o SESI pouco inovou em programas e ações voltados ao trabalhador; sua inserção no concurso para premiar um operário modelo foi uma das poucas novidades implantadas após o golpe civil-militar, uma vez que o contexto político favorecia esse tipo de investida. Para a entidade empresarial essa Campanha se configurava num "veículo conveniente para um discurso que enfatizava o esforço individual e a cooperação com o patrão como a chave da ascensão social para os operários” (WEINSTEIN, 2000 p. 351).

O concurso envolvia várias etapas até se chegar ao vencedor final, na fase nacional. Primeiramente, eram eleitos os operários nas fábricas. As empresas aderiam espontaneamente à campanha, percebendo-se, pelos documentos analisados na pesquisa, haver maior envolvimento de empresas de grande porte. Escolhidos os operários das fábricas, esses participavam da escolha estadual. Todos os operários padrão estaduais concorriam na fase nacional. Os candidatos se dirigiam ao Rio de Janeiro, onde era feita a seleção, e de lá para Brasília a fim de serem recepcionados pelo Presidente da República. 
Figura 1 - Operário Padrão 1981

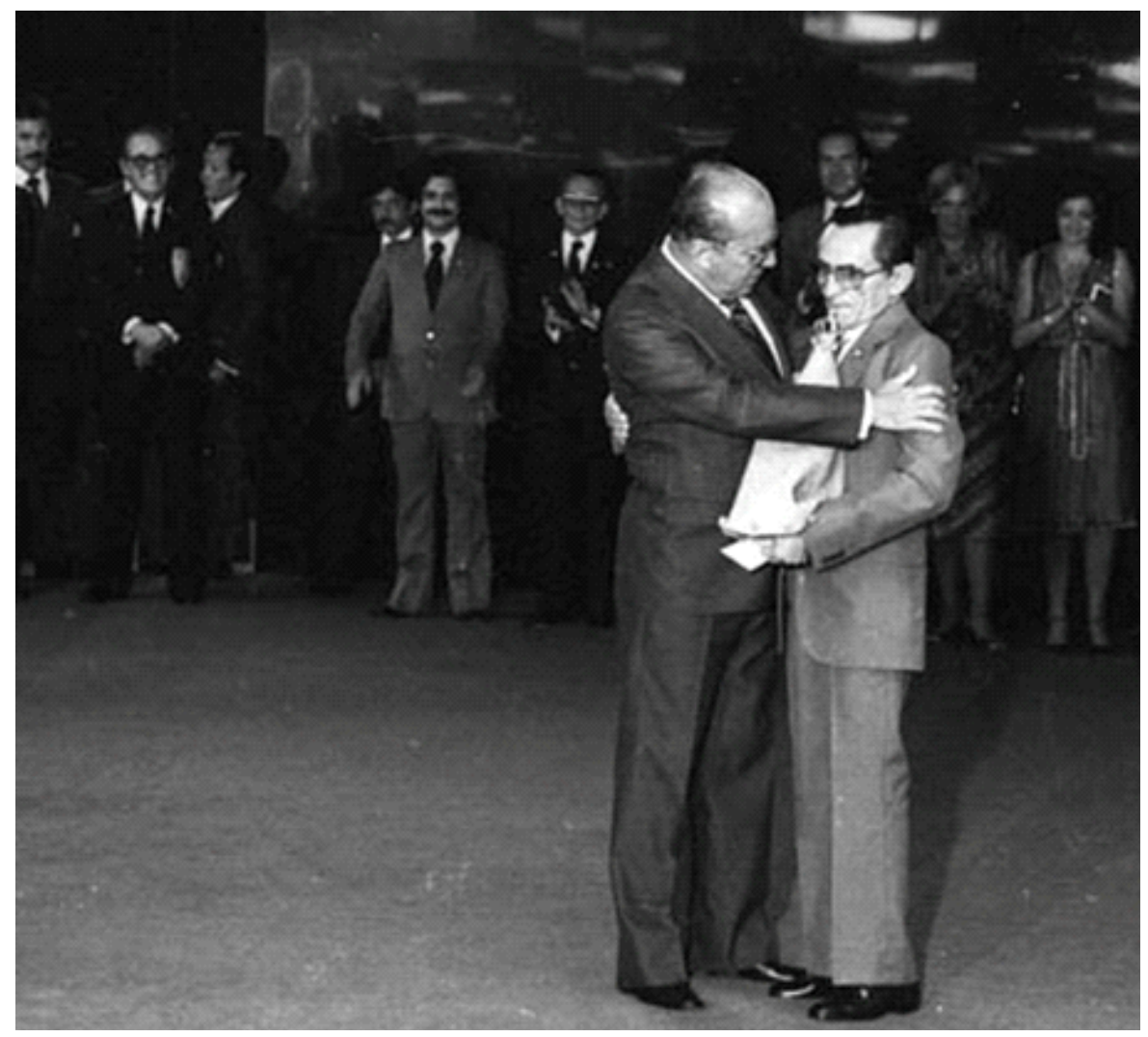

Fonte: Agência O Globo

Para se tornar operário padrão, ou melhor, para obter o título, uma vez que aqueles que se inscreviam no concurso muito provavelmente detinham características de trabalhadores exemplares, o candidato de antemão deveria obedecer a alguns critérios, tais como assiduidade, maior tempo de empresa, cursos realizados e outros quesitos de cunho moral. O operário deveria, ainda, estar ligado às atividades produtivas da fábrica, podendo exercer funções de mestre ou chefe de seção, mas não podia desempenhar atividade administrativa. No tocante às empresas, elas deveriam ser contribuintes do Serviço Social da Indústria (SESI).

Foi possível perceber, pelos documentos analisados, ${ }^{2}$ bem como pela fala de alguns trabalhadores que venceram o concurso, que este se configurava, acima de tudo, como um instrumento de exaltação do trabalho, do labor constante e dedicado - isso em uma sociedade que necessitou "reabilitar o valor do trabalho", especialmente nos anos 30 do século passado.

\footnotetext{
${ }^{2}$ Os documentos utilizados para análise do problema de pesquisa trabalhado na tese foram os materiais produzidos pelo SESI durante os anos de vigência do concurso, além dos currículos dos trabalhadores que participaram da campanha.
} 
Ele também era, a partir desse objetivo principal, um modo de adequar a força de trabalho, de discipliná-la, segundo as concepções morais e econômicas de uma boa parcela do empresariado nacional, por meio de seu órgão social, o SESI.

A compreensão do disciplinamento da mão de obra por meio do discurso do bom operário encarnado pelo operário padrão $(\mathrm{OP})$ não pode se descolar do contexto político vivido pelo Brasil a partir da segunda metade dos anos 1960, quando da implantação de uma ditadura. Como já enunciado, a Campanha Operário Padrão (COP) foi uma das iniciativas voltadas aos trabalhadores mais significativas do empresariado nacional nesse contexto político.

\section{A CAMPANHA OPERÁRIO PADRÃO COMO PRÁTICA DISCIPLINADORA}

A Campanha Operário Padrão (COP) foi uma ação da classe empresarial, através do SESI, ainda que tenha sido idealizada pelo jornal $O$ Globo e que tenha contado com a colaboração deste durante toda sua vigência. Com ela, desejava-se divulgar o perfil do trabalhador ideal e procurava-se, por meio de uma ação nacional, estender um padrão para todos os trabalhadores, especialmente àqueles ligados à indústria, e, dessa forma, disciplinar a mão de obra. Esse disciplinamento, parece-nos, nesse contexto, adquiriu um caráter sutil, pois não era uma conformação forçada, mas, sim, uma prática que tinha o objetivo de premiar o melhor, o mais dedicado, aquele que demonstrou, por anos, estar atento à lógica da produção e que conseguiu relativo sucesso material por meio de seu trabalho, sem, para isso, precisar entrar em conflito com o empresariado. A COP foi uma importante ação que encontrou um contexto ideal: um regime ditatorial.

Acredita-se, a partir da análise dos documentos, que o trabalhador que participava do concurso o fazia, inicialmente, porque a empresa o escolhia, sendo que alguns desconheciam a campanha antes disso, o que revela que o concurso tinha mais valor para a empresa, a qual também se beneficiava de ter um operário exemplar, do que para os próprios trabalhadores. Após participar e, eventualmente, ser escolhido OP, o discurso sobre o evento considerava este como algo muito positivo para todos os trabalhadores e inclusive importante à indústria no progresso nacional (SESI-DN, 1979, p. 1). Nos objetivos da Campanha, dizia-se que, para a empresa, era importante a participação, pois ela "é um elo a mais de ligação entre os patrões e operários", também porque, "ao exaltar o trabalhador, a campanha valoriza a empresa [a] que ele pertence e que lhe dá os meios necessários para desenvolver o seu trabalho" (SESI-RS, 1974, p. 1). 
A principal virtude que o operário deveria demonstrar era sua dedicação ao trabalho. Para comprová-la, seu depoimento ou documentos funcionais não eram suficientes. Segundo regulamento do concurso, isso deveria ser atestado pela chefia imediata. Logo, se não houvesse a concordância dos seus superiores hierárquicos, o trabalhador não participaria do concurso. A interpretação desse item era norteada pela comprovação do "esforço e boa vontade do empregado em bem desempenhar suas funções" (SESI-RS, 1974, p. 1). Os avaliadores também deveriam considerar situações excepcionais em que se atestaria a diligência em relação ao trabalho, como, por exemplo, "um princípio de incêndio em que o empregado tenha ajudado a apagar, trabalho em horário extra durante prolongado período de tempo para resolver uma emergência qualquer que atingiu a empresa, etc.” (SESI-RS, 1974, p. 1). Ademais, ser devotado ao trabalho significava ter recebido promoções, nunca ter sido repreendido ou punido, ser alvo de elogios, e, fundamentalmente, ter "comportamento disciplinar" (SESI-RS, 1974, p. 1). Nesse caso, importavam mais os aspectos comportamentais que a capacidade técnica.

O discurso sobre os objetivos da campanha estava relacionado à promoção do bem-estar do trabalhador, tal como se percebe nos documentos analisados. Dessa forma, "a Campanha Operário-Padrão [tinha] como objetivo maior valorizar o trabalhador e a própria Empresa, aproximando o SESI aos meios empresarial, sindical, autoridades e Entidades, visando ao bemestar do trabalhador" (SESI-DN, 1975, p. 1).

Para além do que estava aparente, havia um discurso subjacente que desejava promover a adequação do conjunto do operariado segundo padrões estabelecidos pelo empresariado nacional: vida exemplar, apego às relações familiares (família de tipo patriarcal), práticas religiosas cristãs (preferencialmente católicas) e valorização do progresso material obtido através do trabalho. A disciplina inerente ao concurso deveria, conforme Mendoza (1991, p. 19), "construir y dar continuidad a un determinado orden productivo, a un sistema de autoridad, dominio y jerarquía aplicado a la producción”.

A coordenadora nacional da Campanha, Sra. Áurea Fialho, afirmava que o objetivo do SESI, ao dirigir o evento, era o de

Estimular os bons operários que pudessem servir de exemplo aos demais trabalhadores, pelo preenchimento de condições sócias e profissionais. Premiar o aumento da produtividade, méritos e conduta exemplar. Consagrar o trabalho anônimo dos que constroem a base do desenvolvimento do país. (FIALHO, 2009).

Certamente esse era um discurso disciplinador, mesmo porque a própria palavra "disciplina" constava no regulamento e nos demais documentos do concurso. Partindo dos 
conceitos elaborados por Foucault, a disciplinarização, neste caso, deveria ocorrer identificando e premiando o "bom exemplo", e não punindo aqueles que não se enquadravam nos preceitos estabelecidos.

Também é preciso pensar de que forma a noção de tempo (fabril, maquínico, disciplinado), relacionava-se com os objetivos da Campanha Operário Padrão. À primeira vista, estabelece-se uma relação na valorização dos itens "assiduidade" e "pontualidade" para o trabalhador participante. Como, em um primeiro momento, a indicação do OP nas empresas era realizada pelas chefias, a escolha do trabalhador estaria adequada a essas normas.

O discurso da Campanha não era de eliminação dos "maus", mas sim de estímulo a que, a partir de um dado exemplo, os outros empregados também se conformassem à realidade que se pretendia. Segundo Michel Foucault (1987, p. 151),

A divisão segundo as classificações ou os graus tem um duplo papel: marcar os desvios, hierarquizar as qualidades, as competências e as aptidões; mas também castigar e recompensar. (...) A disciplina recompensa unicamente pelo jogo das promoções que permitem hierarquias e lugares; pune rebaixando e degradando.

Seguir uma religião era um princípio do concurso. Preferencialmente, o trabalhador deveria ser ativo na comunidade religiosa e isso era sobremaneira valorizado, como se depreende da leitura dos currículos. A "vida comunitária" era entendida, basicamente, pelas atividades de cunho religioso ou vinculadas a uma instituição religiosa, o que pode ser verificado em documento que instruía sobre os requisitos exigidos pelo concurso, posto que "o fato de o empregado fazer ou haver feito parte da diretoria de tais entidades [religiosas] valorizará ainda mais sua atuação" (SESI-RS, 1974, p. 1). Até mesmo quando se pensou em revisar as diretrizes da Campanha, não se discutiu sobre a exclusão ou relativização desse quesito. O pertencimento a um grupo religioso, preferencialmente de confissão católica, tinha um caráter moralizador, era um comprovante seguro de que aquele trabalhador defendia ou era adepto de valores morais condizentes com aqueles propalados pelo SESI. Ademais, a Igreja é um importante instrumento de controle social, especialmente quando se pensa em seus setores mais conservadores. Ser um fiel seguidor das concepções religiosas, durante os anos 60 e 70 do século passado, também podia significar indiferença ou aversão ao discurso comunista, tão combatido nessa época.

A dedicação incondicional à família também era um requisito de grande valor para se tornar um OP. Uma família geralmente numerosa, como era o caso desses trabalhadores, constituía mais uma garantia moral. Determinada disciplina fabril toma de empréstimo 
elementos familiares, especialmente relacionados à figura do pai. Na sua unidade familiar, o operário padrão é o chefe, aquele que provê as condições materiais de existência da família. $\mathrm{Na}$ empresa, por sua vez, "el patrón es esa figura social que administra, 'como buen padre de familia', un patrimonio particular constituido por la fabrica pero también por todo aquello que hace posible da vida de esa 'familia' al margen del trabajo" (GAUDEMAR, 1991, p. 76). Assim, o concurso valorizava a hierarquia que deveria existir na fábrica e nas relações sociais, mas de uma forma humanizada.

Para o SESI, a participação do operário no concurso poderia the oportunizar algo único na vida: "ser um trabalhador modelo, um padrão". Para a entidade social, significava, ao menos no discurso oficial, ir "ao encontro de seu grande objetivo: a paz social no Brasil" (SESI-DN, 1982, p. 1).

A atuação do SESI, além de promover a valorização da atuação do trabalhador e de contribuir para seu bem-estar social (e de seus dependentes), o que é óbvio e incontestado, também resulta em especiais vantagens para as empresas empregadoras, embora de forma indireta, mas nem por isso menos real e palpável. (SESI-RS, 1976, p. 4).

Pode-se pensar que a Campanha Operário Padrão, sob a ótica dos mecanismos de disciplinamento, atuava pedagogicamente sobre os trabalhadores, ao ensiná-los como agir, dentro e fora da fábrica, a fim de alcançar sucesso material e social. Assim, a partir do que foi referido sobre a disciplina ou sobre o poder disciplinar, segundo Foucault, é possível entender os objetivos dos mecanismos que agem nesse sentido: extrair do corpo o máximo de suas forças, produzindo ações e comportamentos de ajustamento, submetendo e sujeitando os corpos, mas também indivíduos capazes e com aptidões determinadas (ARAÚJO, 2012). De outra parte, também se compreende que o operário padrão representava um modelo que atingiu relativa estabilidade material, mesmo porque não se tratava de um simples operário, mas sim de trabalhadores que desempenhavam algum cargo de chefia. A perspectiva de melhoria de vida ou padrão social podia ser o maior atrativo para os demais trabalhadores. A mensagem subliminar contida nas normas e procedimentos do concurso era a de que, se o trabalhador seguisse os preceitos morais e, principalmente, trabalhasse com dedicação e disciplina, poderia melhorar seu nível de vida. 


\section{A CAMPANHA OPERÁRIO PADRÃO E O CONTEXTO POLÍTICO}

Se o concurso que premiava o trabalhador ideal iniciou em meados da década de 1950, foi a partir decênio seguinte e, mais ainda, nos anos 1970 que teve um funcionamento pleno e que abrangeu todo o território nacional. Weinstein (2000) indica, em seu estudo sobre o SESI, que o contexto dos anos de 1960 e 1970 tornou favorável o sucesso da iniciativa. A paz social que se buscava pela integração e harmonia entre as classes possuía mais sentido num governo ditatorial.

A participação do Estado na Campanha se estabelecia pelo envolvimento do Ministério do Trabalho na fase de julgamento, tanto estadual - através das secretarias - quanto nacional pela presença do próprio Ministro. Esse órgão também outorgava uma medalha (mérito ao trabalho) aos operários vencedores. Além disso, o presidente da República recebia os operários ao final de cada edição do concurso e, com isso, reforçava a ideia de prestígio que se destinava ao exemplo do operariado nacional, bem como reverenciava aquele trabalhador que estava alinhado à perspectiva de harmonia entre as classes. Nessa cerimônia de encontro também estava presente o Ministro do Trabalho. Segundo o titular da pasta nos anos 1970, Arnaldo Prieto, a campanha vinha "ao encontro dos altos objetivos do governo do Presidente Ernesto Geisel que tem, no homem brasileiro, a preocupação maior de todo o planejamento nacional”. Ele ainda acrescenta que a iniciativa deveria servir de "estímulo e inspiração aos trabalhadores brasileiros", pois, dessa forma, estariam "consolidando a paz social que desfrutamos em nosso país". 3

A integração entre as classes desejada pelo governo e pelos empresários era perseguida exaltando o tipo de trabalhador aclamado pelo concurso, mas também sufocando possíveis movimentos sindicais, minimizando a participação social dos operários. Além disso, apesar do crescimento apresentado pelo "milagre econômico", pouco desse crescimento chegou de fato aos trabalhadores nacionais, pois, conforme Matos (2009, p. 109), esse foi um período de "arrocho salarial e [de] superexploração da força de trabalho que, garantidos pelo controle do governo sobre os sindicatos, elevavam em muito a lucratividade do capital". Portanto, apesar do discurso de valorização do trabalhador nacional como o produtor de riqueza, não havia uma política econômica de fato voltada para a melhoria de vida dessas pessoas.

\footnotetext{
${ }^{3}$ Trecho de carta enviada pelo Ministro do Trabalho a Roberto Marinho, publicada no jornal $O$ Globo de 4 de setembro de 1975.
} 
A indústria nacional foi beneficiada pelas políticas econômicas da ditadura, especialmente no período do "milagre", mesmo que à custa de endividamento externo. No âmbito do concurso, também se procurou exaltar o papel da indústria nacional. Em algumas edições, particularmente na década de 1970, o candidato deveria responder em seu currículo qual era "papel da indústria no progresso nacional", mesmo que não tenham sido localizadas, nos currículos examinados, respostas a esse questionamento.

No início da década de 1980, ainda sob os auspícios de uma ditadura, presenciava-se uma abertura política controlada pelo governo, desde o final da outra década, e o ressurgimento do movimento sindical. Ainda assim, o Estado nacional continuou participando e exaltando o concurso. Em 1981, o presidente João Figueiredo, ao receber os operários vencedores daquele ano, associou a seleção deles, operada pelo SESI, a uma prática do Exército:4

[...] devo ressaltar que a cerimônia de hoje se destaca porque me lembra, muitas vezes, aquelas em que tomei parte no Exército, em que também era obrigado a destacar, entre os meus soldados, aquele que por suas virtudes morais e pela sua dedicação ao serviço e a instrução tinha servido de exemplo para os seus companheiros (FIGUEIREDO..., 24 nov.1981. n. p).

Os organizadores do concurso estavam atentos às transformações sociais que vinham ocorrendo na política nacional, especialmente no que tangia à maior abertura, aos movimentos sociais voltando à vida nacional e, em particular, ao movimento operário que renascia com as greves no Grande $\mathrm{ABC}$ paulista. Isso parecia preocupar um pouco os patrocinadores, porque o operário que se desejava não era aquele reivindicativo, então, era necessário reafirmar os objetivos do concurso. Por conseguinte, deveriam ser enfatizados valores como a paz social, a manutenção da hierarquia, a disciplina e a participação operária ordeira.

Eu sei perfeitamente que agora nós tivemos, já nessa fase de "abertura", esses movimentos operários sindicais. Aí são reivindicações, digamos materiais e imediatas, enquanto em nosso campo praticamente é de outro tipo; quer dizer, o Operário-Padrão seria muito bem-vindo se ele estivesse participando de algum conselho municipal em âmbito menos de contribuição, com ideias à frente de todos, nos problemas do sindicato (SESI-DN, 1979, p. 13).

Assim, ao mencionar o movimento reivindicativo protagonizado pelas entidades sindicais, o SESI procurava desqualificá-las afirmando que estas possuíam um caráter apenas

\footnotetext{
${ }^{4}$ Gaudemar (1991) e, especialmente, Foucault (1987) indicaram a apropriação de modelos da disciplina militar para eficácia da disciplina fabril no início da "era da disciplina".
} 
material e imediatista, ao passo que promovia a exaltação dos propósitos da Campanha, que visavam a um bem maior.

[...] trata-se da exaltação do trabalho pelo trabalho, da glorificação do trabalho, em que não há nenhuma vantagem imediata para o trabalhador [...] a maior gratificação é o reconhecimento das virtudes do trabalhador e a gratificação de representar o trabalhador [...] Nós estamos agora, depois de quinze anos de Revolução, estamos empenhados num esforço muito grande que se convencionou chamar de "abertura". Este esforço, evidentemente, é no sentido de procurar, para a nação brasileira, um estatuto jurídico, ou um regime, um sistema, ou uma vida jurídica que propicie o máximo de realização individual, e nisso se considera a pessoa humana, dentro da ordem e da disciplina. Evidentemente, tivemos um período de restrições e agora caminhamos para a chamada manifestação (SESI-DN, 1979, p. 11).

Em 1985, a propaganda destinada à divulgação da Campanha, transmitida pela Rede Globo e também veiculada em seu jornal, mencionava a necessidade de eleições diretas para a escolha do OP. Como vimos na pesquisa, o OP de cada fábrica era indicado por setores hierárquicos mais altos da empresa e, depois disso, poderia haver eleição entre os trabalhadores ou se aclamava o indicado pelas chefias. Com o advento de manifestações sociais pela aprovação da Emenda Constitucional Dante de Oliveira, concentrada na Campanha Diretas Já, em 1983, tornava-se difícil para os meios de comunicação ou para outras instituições a continuidade do apoio antes dado ao regime ditatorial. ${ }^{5}$ A COP, mais uma vez, acabou por incorporar o que ocorria na sociedade como tentativa de se modernizar.

Ao findar o período da ditadura, o concurso não teve duração mais prolongada, pois se questionava a validade desse tipo de iniciativa, inclusive no próprio âmbito empresarial.

\section{A ADESÃO EMPRESARIAL AO CONCURSO}

A Campanha Operário Padrão mobilizava esforços dos seus envolvidos durante, pelo menos, seis meses do ano. Havia uma equipe responsável no Departamento Nacional da entidade e também nos Departamentos Regionais. $\mathrm{O}$ aparato e o planejamento que a iniciativa demandava supunham um extenso interesse por parte de seus organizadores e dos demais

\footnotetext{
${ }^{5}$ A própria Organizações Globo, em sua página institucional, menciona a necessidade que teve, no período, de se adequar à nova realidade brasileira, ainda que, de acordo com o explicitado na página "a pressão dos militares sobre a Rede Globo atingiu o seu ápice", tomando “a forma de intimidação pessoal” (DIRETAS JÁ, 2013). Antes apoiadora e alvo de benefícios do regime, em seguida, ela adapta seu discurso por ser repreensível a continuidade do apoio.
} 
empresários pelo país. O concurso deveria mobilizar, primeiramente, os donos das empresas para que, posteriormente, chegasse até os seus operários.

Porém, segundo Weinstein (2000, p. 352), apesar dos esforços do SESI e da propaganda do jornal $O$ Globo, "somente uma pequena fração das empresas, mesmo das maiores, participou de forma efetiva do concurso". Os dados relativos à participação dos empresários gaúchos também dão conta disso, desde o início do concurso até o seu final.

No final dos anos 1970 e no início da década seguinte, com vistas ao processo de abertura política que a ditadura promovia por pressões advindas de vários grupos da sociedade, alguns envolvidos com o concurso consideraram era importante que este também se adequasse aos novos tempos, pois estava associado sobremaneira ao governo militar. Assim, percebem-se críticas à Campanha provenientes tanto do Departamento Nacional como dos Departamentos Regionais do SESI. Em setembro de 1981, o presidente do Conselho Nacional do SESI, ao anunciar a concessão dos prêmios para os OPs daquele ano, informava ao Diretor do DN que “a respeito da Campanha em curso, [...] particularmente dirigida por esse Departamento Nacional, vem ocorrendo manifestações isoladas questionando a validade de tal evento" (SESIDN, 1981, p.1). Como resultado desses questionamentos, realizou-se o II Encontro de Coordenadores.

Mesmo após a realização de tal evento, ${ }^{6}$ em que se discutiram algumas reformulações no concurso (inclusive não denominar mais a iniciativa de "concurso", mas usar a nomenclatura “campanha"), o Departamento Regional do Rio Grande do Sul encaminhou suas críticas ao DN a partir de uma pesquisa realizada no estado. O estudo, segundo o documento,

[...] preconiza[va] uma profunda reformulação dessa Campanha, visando adequá-la aos dias atuais, de forma a acompanhar as sensíveis transformações que se verificaram ao longo dos anos na sociedade brasileira, inclusive no seio da classe operária à qual se dirige a promoção.

Vem já de vários anos a preocupação do SESI gaúcho, seja do Conselho Regional, seja da Direção do DR, de buscar uma forma de melhorar a imagem da "Campanha Operário Padrão" perante os trabalhadores e a própria opinião pública.

Aqui no Rio Grande do Sul, a sua realização, nos moldes atuais, está totalmente desacreditada, como se pode verificar dos depoimentos colhidos [...] (SESI-RS, 1981, p. 1).

\footnotetext{
${ }^{6}$ No II Encontro de Coordenadores, realizado em abril de 1981, criticou-se muito a respeito da pouca divulgação do evento, sendo solicitado maior divulgação por parte do SESI e do jornal $O$ Globo. Sugeriu-se que, além da divulgação no jornal e no rádio, fosse usada também a televisão, procurando informar um maior número de pessoas. Parece que essa foi a resolução mais importante do encontro.
} 
A investigação sobre o tema realizada pelo SESI do Rio Grande do Sul identificou baixa adesão das empresas ao concurso, com uma média anual de participação, até aquela data, de menos de $1 \%$ do total das empresas do estado. Nos depoimentos coletados, procurava-se passar a impressão de que o concurso estava descolado da situação social brasileira, especialmente dos trabalhadores. Os depoimentos expunham a falta de participação dos sindicatos dos trabalhadores, além de exibirem severas críticas a sua manutenção, como a que afirmava que o evento "[parecia] muito mais uma promoção para amenidades e muito pouco uma real preocupação pelos efetivos, graves e grandes problemas com que se debate o trabalhador brasileiro" (SESI-RS, 1981, p. 2).

Algumas opiniões eram favoráveis ao certame, dizendo que se tratava de uma grande iniciativa, mas outras eram bem contundentes, defendendo a não continuidade da promoção, como a de um profissional liberal que afirmou que "a promoção é ridícula. É um acinte à situação do trabalhador brasileiro" (SESI-RS, 1981, p. 3). A existência de depoimentos criticando uma iniciativa do próprio SESI estava menos relacionada com um juízo aos objetivos do concurso do que com a conquista de maior autonomia pelos Departamentos Regionais na organização do concurso, objetivo maior do estudo realizado e exposto no final do documento, pois a autonomia acarretaria respostas "às peculiaridades locais e regionais" (SESI-RS, 1981, p. 4).

Conquanto as queixas e, de acordo com informações do Departamento Regional do Rio Grande do Sul, da fraca participação das empresas nesse estado, o Departamento Nacional continuava incentivando o concurso defendendo que "milhões de trabalhadores, em milhares de fábricas, de todos os estados, participam diretamente da Campanha Operário-Padrão" (SESIRS, 1982, p. 2). Assim, apesar das críticas e das dificuldades apontadas por alguns Departamentos Regionais na realização do concurso, o II Encontro dos Coordenadores da Campanha ratificou sua padronização de normas e procedimentos, os quais deveriam ser adotados por todos os Departamentos Regionais. Não se identificou a realização de outro seminário, nos moldes dos anteriormente organizados, para discutir os rumos do concurso.

De fato, a iniciativa persistiu por mais alguns anos, mas a partir de 1987, em uma tentativa de "modernizar" o concurso, $O$ Globo e SESI modificaram seu nome. Deixou-se de lado o nome Operário Padrão, que foi substituído pelo Operário Brasil. Entretanto, verificouse que, naquele momento, a mudança foi apenas na nomenclatura, pois as diretrizes e os objetivos que envolviam o evento pouco se modificaram. 
Considerando estas distintas fases, e apesar das críticas, o concurso durou até o ano de 1995, ou seja, foi uma iniciativa que perdurou por quatro décadas.

\section{REFERÊNCIAS BIBLIOGRÁFICAS}

ARAÚJO, Inês Lacerda. Vigiar e punir ou educar? Biblioteca do Professor: Foucault, São Paulo, n. 3, p. 26-35, 2012.

DIRETAS JÁ. Memória Globo, 2013. Disponível em:

$<$ http://memoriaglobo.globo.com/erros/diretas-ja.htm>. Acesso em: 20 dez. 2013.

FIALHO, Áurea. Áurea Fialho: Depoimento [2 nov. 2009]. Entrevistador: Daniela de Campos. Rio de Janeiro: 2009. Entrevista concedida por mensagem eletrônica.

FIGUEIREDO recebe Operários-Padrão e diz que são a força propulsora da sociedade. O Globo, Rio de Janeiro, 24 nov.1981. n. p.

FOUCAULT, Michel. Vigiar e Punir. 21. ed. Petrópolis: Vozes, 1987.

GAUDEMAR, Jean-Paul. El orden y la producción. Nacimiento y formas de la disciplina de fábrica. Madrid: Trotta, 1991.

MATOS, Marcelo Badaró. Trabalhadores e sindicatos no Brasil. São Paulo: Expressão Popular, 2009.

MENDOZA, Carlos Alberto Castillo. Estudio introductorio. In: GAUDEMAR, Jean-Paul. El orden y la producción. Nacimiento y formas de la disciplina de fábrica. Madrid: Trotta, 1991.

O HOMEM QUE VIROU SUCO. João Batista Andrade. São Paulo: Embrafilme; Secretaria de Cultura do Estado de São Paulo, 1979. DVD.

Serviço Social da Indústria - Departamento Nacional - SESI-DN. Objetivos da Campanha Operário-Padrão, 1975.

. I Encontro de Coordenadores da Campanha Operário Padrão. Rio de Janeiro, 1979. 
. Ofício CONGAB 119/81. 1981.

. Campanha Operário Padrão. 1982.

Serviço Social da Indústria - Rio Grande do Sul - SESI-RS. Concurso Operário Padrão

1974: Interpretação dos requisitos exigidos dos candidatos. 1974.

Concurso Operário Padrão 1976: Relatório. 1976

. Estudo sobre a Campanha Operário Padrão. 1981.

. Campanha Operário Padrão. 1982.

WEINSTEIN, Barbara. The model worker of the paulista industrialists: The "Operário

Padrão” Campaign. Radical History Review, Durham, NC, p. 92-123, 1995.

. (RE)Formação da Classe Trabalhadora no Brasil (1920-1964). São Paulo:

Cortez/CDAPH-IPHAN/Universidade São Francisco, 2000. 